\title{
Citius, Fortius? Cohort, inflammation and trajectories of gait speed and grip strength in older Britons
}

Gindo Tampubolon ${ }^{1}$

Maria Fajarini ${ }^{2}$

1 Manchester Institute for Collaborative Research on Ageing University of Manchester

2 Evidence \& Analytics, Manchester

* tampubolon@manchester.ac.uk

\section{Abstract}

Although the cost of long term care of physical disabilities is considerable, little is known about individual trajectories of physical function (measured by gait speed and grip strength) that preceded the process of disablement. Moreover, studies on trajectories of health function have often ignored cohort composition, precluding evidence of secular improvement. And few have explored the role of chronic inflammation on older people's physical function trajectories. Using the English Longitudinal Study of Ageing 2004

- 2013 we derived trajectories of gait speed and grip strength of Britons aged $\geq 50$ years and investigated the effect of inflammation. Then we drew 
trajectories for different cohorts to seek evidence of secular improvement.

We uncovered a complex gradient of improvement in trajectories of

physical function that depends on sex and maximum versus normal

capacity. In conclusion, accounting for the cohort composition of older

people can materially modify the future cost of long term care.

Keywords: English Longitudinal Study of Ageing; gait speed; grip strength;

inflammation; C-reactive protein; fibrinogen; attrition; weighting

\section{Introduction}

Olympians are not the only group attaining secular improvement over recent decades. The most recent cohort of older people have also showed higher levels of cognitive function [1]. The Post-War cohort, compared to the earlier cohorts, maintained higher episodic memory at similar ages. Given the myriad connections between cognitive and physical functions [2], 6 this evidence raises a possibility that the more recent cohort of older people also maintain an advantaged trajectory of physical function. We interpret inter-cohort (for instance from War cohort to Post-War cohort) increase in functioning as evidence of secular improvement 3].

We tested this possibility by using gait speed and grip strength as two ${ }_{11}$ well-characterised measures of physical function [4] 6 , especially since grip ${ }_{12}$ strength has been shown to predict disability, morbidity, and mortality 7,8 .

Such a possibility can have theoretical and practical implications. Cohort has always been an important concept waiting to take its place in ${ }_{16}$ our scheme of understanding individual change over an extended period of ${ }_{17}$ later life ( $\geq 50$ years). Cohort in our sense is not primarily defined 
chronologically. Instead it refers to a time course or an era defined by socio-historical events, e.g. War vs. Post-War cohort or Pre-Depression era 20 vs. Depression era cohort. But it has rarely been treated as an integral $\quad{ }_{21}$ part, as if by later life age has chiseled off any cohort difference that might $\quad 22$ matter.

However, recent scholarship has questioned this age-as-leveller assumption. Birth cohort, as a marker for a childhood stage exposed to similar kinds of developmental hazards and damage (cf. the War cohort 26 versus the Post-War cohort), can give insight into how later life experience ${ }_{27}$ might unfold. For example, in the English Longitudinal Study of Ageing $\quad 28$ (ELSA), childhood condition at age ten has been found to exert a very $\quad 29$ long influence indeed. Those who were poor financially in their first decade 30 of life displayed slower gait, poorer memory, and more depression in their 31 fifth to ninth decades of life [5]. Because the evidence is based on 32 cross-sectional observations, the study cannot distinguish cohort effect from age trajectory effect. It remains a distinct possibility that a net cohort effect yields insight on how an early stage in life course shapes health outcomes and wellbeing throughout later life.

The implications are not merely theoretical [9]. In practice, cohort effect 37 can have a bearing on policy to support and care for older population, a $\quad 38$ growing and important demographic. For example, two British regions $\quad 39$ with the same number of people aged $\geq 50$ years but different cohort composition are likely to yield different evolution of demand for health and social care. To put a figure on the stake, the Swedish and Dutch governments spent $3.5 \%$ of their gross domestic products on long term care ${ }_{43}$ of older people with disabilities, including physical disabilities (WHO 
World Report on Ageing and Health) [10]. Apart from the difference in

45

their health systems, difference in cohort composition across the two countries can impact future trends of these percentages.

The WHO World Report also emphasised the need for refined pictures of changes in physical function of individuals in later life. This calls for deriving, based on the experience of older people living in communities or outside institutions, age trajectories of physical function over an extended period.

One note of caution follows when deriving such trajectories. Collecting 53 repeated measures from older people inevitably faces attrition problems, $\quad{ }_{54}$ since older people tend to attrite non-randomly in subsequent visits 11,12 . $\quad 55$ Recently, a number of solutions have been proposed including weighting $\quad 56$ and joint modelling [1, 13, 14]; inverse proportional to attrition weighting is $\quad 57$ applied here.

While recent studies on cognitive function and well-being showing cohort improvement have prompted the question on cohort effect [1, 13], another recent study on blood-based biomarkers of cognitive deficits [15 have suggested another insight. The study showed that inflammation, measured using two inflammatory markers of high sensitivity C-reactive protein (CRP) and fibrinogen, is associated with cognitive deficits. So given the connections between cognitive and physical functions [2], inflammation can be expected to have an effect on physical function trajectories throughout later life as well [16]. This can enrich our understanding of key drivers of healthy ageing that affect multiple dimensions of health functions.

We therefore aimed to gauge whether there is a secular improvement to ${ }_{69}$ gait speed and grip strength enjoyed by some older people living today and 70 
to quantify the effect of inflammation on the trajectories of physical

function. We note that our aim was not to estimate causality, merely to

explore important association hitherto neglected. To tie the strands

73

together we raise three questions: What is the shape of age trajectories of 74

physical function as measured by gait speed and grip strength? Do recent 75

cohorts possess a more advantaged trajectory, one with higher levels at $\quad 76$

similar ages to the earlier cohorts? Is inflammation associated with lower $\quad 77$

levels of physical function?

\section{Materials and methods}

The University of Manchester's institutional review board has exempted

this study since it used publicly available anonymised secondary data for $\quad{ }_{81}$ research.

The English Longitudinal Study of Ageing (ELSA) is the main resource 83 for a nationally-representative ageing study of the English older population. $\quad{ }^{84}$ The first wave was in 2002 and subsequent waves follow biennially. waves $(2004 / 5,2008 / 9$ and $2012 / 3)$ when nurses visited the participants. The data are freely available from the UK Data Archive (www.data-archive.ac.uk) as study number 5050. More details of the study 89 are given elsewhere $14,17,19$.

We used two measures of physical function that have been used in this 91 sample [4,5]. The first is gait speed at normal pace $(\mathrm{m} / \mathrm{s})$, timed by a ${ }_{92}$ research nurse, in $\mathrm{m} / \mathrm{s}$; the second is objectively measured maximum grip $\quad 93$ strength of the dominant hand $(\mathrm{kg})$, obtained using a dynamometer $\quad 94$ (Smedley Dynamometer, Tokyo). The nurse demonstrated each test before $\quad 95$ 
the participant was asked to do it. After adjusting the dynamometer to suit the participant's hand and positioning the participant correctly, the $\quad{ }_{97}$ participant was asked to squeeze the dynamometer as hard as possible for 98 a couple of seconds. Three values were recorded for each hand, starting $\quad 99$ with the non-dominant hand and alternating between hands. The 100 maximum was used. Walking speed was measured by marking a course in 101 a suitable space in the participant's home with a tape measure and placing ${ }_{102}$ masking tape at the starting and ending points. The length of the course ${ }_{103}$ was $244 \mathrm{~cm}$. The nurse used a stopwatch to record the time. The 104 participant was asked to complete two timed walks at normal pace. $\quad 105$

Blood samples were collected by the research nurse in three waves and 106 kept deep-frozen until analysis at the Newcastle NHS hospital laboratory. ${ }_{107}$ Plasma samples were analyzed for fibrinogen concentrations (in g/L) using $\quad{ }_{108}$ an ACL TOP CTS analyzer. The samples were also analyzed for high $\quad{ }_{109}$ sensitivity CRP concentrations (in mg/L), applying a particle-enhanced ${ }_{110}$ immunoturbidimetric assay, using Roche Modular P analyzer. Both have ${ }_{111}$ been used before [15]. Following the literature [15,20,21], we removed 112 observations with CRP concentrations above $10 \mathrm{mg} / \mathrm{L}$, indicating acute $\quad{ }_{113}$ inflammation. Because CRP distribution is skewed, following the Women's 114 Health Initiative Study and Established Populations for Epidemiologic $\quad{ }_{115}$ Studies of the Elderly, we derived an indicator variable marking 116 concentrations in the top quartile; similarly with fibrinogen 22,24$]$. We ${ }_{117}$ constructed four cohorts or birth groups marked by socio-historical events, 118 to make them comparable to the US sister study (Health and Retirement ${ }_{119}$ Survey) and a previous study of this sample [1]. The four cohorts 120 (requiring three cohort indicators) are pre-Depression cohort (born before ${ }_{121}$ 
1930, omitted as the reference), Depression era cohort (1931-1938), War ${ }_{122}$ cohort (1939-1945) and post-War cohort (born after 1946). These four are ${ }_{123}$ more refined than the three cohorts used in the ELSA report [17, 25, 26]. $\quad{ }_{124}$

Following the literature [4, 27] we built separate models for the sexes. ${ }_{125}$ We used mixed model to derive trajectories of both physical function $\quad 126$ measures; the model is variously known as latent growth curve model or $\quad{ }_{127}$ random coefficients model. The dependent variables were gait speed and ${ }^{128}$ grip strength. The key covariates were cohort indicators, high CRP 129 indicator, and high fibrinogen indicator. In applying mixed or random $\quad 130$ coefficients model, we estimated random intercepts, random slopes of age, 131 and their covariance. As confounders we included, in addition to age and ${ }_{132}$ sex other covariates including wealth (in tertiles with the poorest third as ${ }_{133}$ reference), marital status (single, married or partnership, and others as $\quad{ }_{134}$ reference) and socioeconomic positions earlier in the life course: education 135 (threefold: less than high school as reference, high school, and college), and ${ }_{136}$ occupational class (threefold: routine manual as reference, intermediate, 137 and managerial/professional). We also included heigh following similar $\quad{ }_{138}$ studies in Europe and Britain 28 31]. We set an a priori $\alpha=0.05$.

We retained in the analysis those with complete information on both $\quad{ }_{140}$ physical function measures (gait speed and grip strength), both 141 inflammatory markers (CRP and fibrinogen) and other covariates (as $\quad{ }_{142}$ analytic sample). This resulted in $N=5,030$ at baseline, and 5,384 and ${ }_{143}$ 4,500 at subsequent waves. The analytic and reference samples were tested ${ }_{144}$ for difference using $t$ test (continuous covariates) and $\chi^{2}$ test (nominal $\quad{ }_{145}$ covariates). At baseline, the analytic sample (compared to the reference $\quad{ }_{146}$ sample) had relatively younger participants (66.0 [standard deviation/SD $\quad{ }_{147}$ 
9.1] vs 69.6 [SD 9.9]), $t=12.4, p<0.001$, lower CRP levels $\left(2.6\right.$ [SD 2.3] ${ }_{148}$

vs $2.9[\mathrm{SD} 2.3]), t=2.3, p=0.020)$, and lower fibrinogen levels $\left(3.1\left[\mathrm{SD} \quad{ }_{149}\right.\right.$

$0.6]$ vs 3.3 [SD 0.9], $t=3.5, p<0.001)$, higher gait speed $\left(1.1\right.$ [SD 0.3] ${ }_{150}$

vs $1.0[\mathrm{SD} 0.4] \mathrm{m} / \mathrm{s}, t=5.4, p<0.001)$, and stronger grip strength $\left(\begin{array}{ll}29.7 & \\ & \end{array}\right.$

[SD 10.7] vs $28.2[\mathrm{SD} 10.8] \mathrm{kg}, t=2.4, p=0.015)$. Both samples had a ${ }_{152}$ higher proportion of women to men (analytic sample: 0.53, SD 0.49; 153 reference sample: 0.56 , SD 0.49) but there was no significant difference $\quad{ }_{154}$ between the samples $\chi_{1}^{2}=2.2, p=0.14$ 155

Because the repeated observations had shrunk due to attrition, we 156 followed the extensive literature in using inverse proportional to attrition $\quad{ }_{157}$ weighting 32 35]. Particularly following [35], the attrition model included 158 age, sex, smoking, cognition, education, hypertension, cardiovascular $\quad 159$ disease, diabetes, and retirement status; then stabilised weights were $\quad 160$ computed with base model including age, sex, and education. All 161 modelling was done in Latent GOLD Syntax 5.1 36].

\section{Results}

Women made up the majority of the sample $(8,142 ; 54.6 \%)$ while the average gait speed at normal pace was $1.1 \mathrm{~m} / \mathrm{s}$ (standard deviation [SD] ${ }_{165}$ $0.4 \mathrm{~m} / \mathrm{s}$ ), of maximum grip strength was $29.5 \mathrm{~kg}(\mathrm{SD} 11.5 \mathrm{~kg})$, and of age ${ }_{166}$ was 66.4 year (SD $8.9 \mathrm{yr}$ ); see Table 1 .

To gauge cohort effect initially, we computed proportions for all cohorts 168 of people who were physically impaired based on thresholds recently established for the British population, i.e. 1.5 standard deviation below 170 the mean (sex and yearly-age standardised) [4]. The cross-cohort 171 proportions in Table 2 present, with a slight tapering off, a gradient of 172 


\begin{tabular}{|c|c|c|}
\hline Variable & mean or $N$ & Std. Dev. or $\%$ \\
\hline Gait speed & 1.1 & 0.4 \\
\hline Grip strength & 29.5 & 11.5 \\
\hline CRP & 2.5 & 2.3 \\
\hline Fibrinogen & 3.1 & 0.6 \\
\hline Age, year & 66.4 & 8.9 \\
\hline Men & 6,772 & 45.4 \\
\hline Women & 8,142 & 54.6 \\
\hline \multicolumn{3}{|l|}{ Marital status } \\
\hline Single & 830 & 5.6 \\
\hline Married & 10,272 & 68.9 \\
\hline Separated/widowed* & 3,812 & 25.6 \\
\hline \multicolumn{3}{|l|}{ Social class } \\
\hline Managerial & 5,882 & 39.4 \\
\hline Intermediate & 3,544 & 23.8 \\
\hline Routine manual* & 5,488 & 36.8 \\
\hline \multicolumn{3}{|l|}{ Wealth } \\
\hline Poorest* & 4,198 & 28.2 \\
\hline Middle & 5,139 & 34.51 \\
\hline Wealthiest & 5,577 & 37.4 \\
\hline \multicolumn{3}{|l|}{ Education } \\
\hline Less than high school* & 4,619 & 30.9 \\
\hline High school & 5,737 & 38.5 \\
\hline Some college & 4,558 & 30.6 \\
\hline
\end{tabular}

Table 1. Description of analytic sample with reference categories in asterisks. Source: ELSA 2004-2013.

improvement as shown in reduction in impairment across cohort. Nearly $\quad{ }_{173}$ $4.5 \%$ of Pre-Depression cohort members were impaired compared to only ${ }_{174}$ $2.4 \%$ of the Post-War cohort members.

To gain better insights we included other covariates in models of physical function. Model fit statistics, presented in Table 3, suggest that, ${ }_{177}$ as with Danish data [29], non-linear age trajectories fit the data best 178 (smallest BIC and largest $\mathrm{R}^{2}$ ). Subsequent presentation relies on these four ${ }_{179}$ models (two outcomes for both sexes) with age and squared age terms. $\quad 180$

The coefficients of the best models for gait speed are given in Table 4 and for grip strength in Table 5. Table 4 showed that there is no difference ${ }_{182}$ 


\begin{tabular}{lrr}
\hline Cohort & \multicolumn{2}{c}{ Impaired } \\
& Yes & No \\
\hline Pre-Depression & 4.45 & 95.55 \\
Depression cohort & 3.17 & 96.83 \\
War cohort & 2.19 & 97.81 \\
Post-War & 2.36 & 97.64 \\
Total & 2.77 & 97.23 \\
\hline
\end{tabular}

Table 2. Proportion of physically impaired older people in each cohort based on British population reference values. Source: ELSA 2004-2013.

\begin{tabular}{llrrrr}
\hline & & \multicolumn{2}{c}{ Age } & \multicolumn{2}{c}{ Age $^{2}$} \\
& & BIC & $\mathrm{R}^{2}$ & BIC & $\mathrm{R}^{2}$ \\
\hline Women & Gait speed & 2121.794 & 0.434 & 1707.843 & 0.705 \\
Men & & 956.636 & 0.720 & 598.624 & 0.735 \\
Women & Grip strength & 55612.431 & 0.127 & 55612.656 & 0.569 \\
Men & & 47187.521 & 0.788 & 47185.125 & 0.789
\end{tabular}

Table 3. Model fit for gait speed and grip strength. Source: ELSA 2004 -2013 .

in gait speed at normal pace among those who were born during different $\quad 183$ times in the last century. Compared to those born before 1930 (the 184 reference), men and women of the three subsequent cohorts of Depression $\quad 185$ era, War and Post-War cohorts walked no faster. Both sexes however $\quad 186$ showed similar reduction in gait speed with high levels of C-reactive $\quad 187$ protein: women by $0.023 \mathrm{~m} / \mathrm{s}$ (95\% confidence interval, CI: $0.037-\quad 188$ $0.090 \mathrm{~m} / \mathrm{s}$ ) and men by $0.027(\mathrm{CI}: 0.011-0.043 \mathrm{~m} / \mathrm{s})$. 189

Compared to the estimates for gait speed, those for maximum grip 190 strength showed similarities and differences (Table 5). There is a 191 discernible and different pattern of cohort effect. Men of the three 192 subsequent cohorts displayed a step by step increase in maximum grip $\quad 193$ strength by about one kg per cohort, amounting to a cohort gradient or $\quad{ }^{194}$ secular improvement. For the two most recent cohorts, this improvement is 195 also highly statistically significant. There is also some similarity with the ${ }_{196}$ results on gait speed (Table 4) in the inverse association between ${ }_{197}$ 


\begin{tabular}{|c|c|c|c|c|c|c|}
\hline \multirow[t]{2}{*}{ Gait speed } & \multicolumn{3}{|c|}{ Women } & \multicolumn{3}{|c|}{ Men } \\
\hline & coef & s.e. & $\mathrm{p}$ & coef & s.e. & $\mathrm{p}$ \\
\hline Constant & 7.301 & 0.203 & $<0.001$ & 7.241 & 0.216 & $<0.001$ \\
\hline Age & -0.160 & 0.006 & $<0.001$ & -0.158 & 0.007 & $<0.001$ \\
\hline Age2 & 0.098 & 0.005 & $<0.001$ & 0.097 & 0.005 & $<0.001$ \\
\hline \multicolumn{7}{|c|}{ Cohort: Pre-Depression as reference } \\
\hline Depression era & 0.021 & 0.021 & 0.31 & 0.016 & 0.023 & 0.47 \\
\hline War & -0.042 & 0.027 & 0.11 & -0.047 & 0.029 & 0.10 \\
\hline Post-War & 0.036 & 0.032 & 0.26 & 0.010 & 0.035 & 0.77 \\
\hline Height & -0.000 & 0.000 & 0.001 & -0.000 & 0.000 & 0.008 \\
\hline \multicolumn{7}{|c|}{ Wealth: poorest third as ref. } \\
\hline Middle & 0.013 & 0.008 & 0.098 & 0.003 & 0.008 & 0.70 \\
\hline Wealthiest & 0.042 & 0.008 & $<0.001$ & 0.030 & 0.009 & $<0.001$ \\
\hline \multicolumn{7}{|c|}{ Education: primary school as ref. } \\
\hline High school & 0.031 & 0.008 & $<0.001$ & 0.039 & 0.009 & $<0.001$ \\
\hline College & 0.039 & 0.011 & $<0.001$ & 0.056 & 0.010 & $<0.001$ \\
\hline \multicolumn{7}{|c|}{ Occupation: routine manual as ref. } \\
\hline Managerial & 0.028 & 0.010 & 0.003 & 0.024 & 0.008 & 0.003 \\
\hline Intermed & 0.016 & 0.008 & 0.047 & 0.015 & 0.012 & 0.22 \\
\hline \multicolumn{7}{|c|}{ Marital status: separated/widowed as ref. } \\
\hline Single & 0.006 & 0.016 & 0.71 & 0.002 & 0.015 & 0.90 \\
\hline Married & -0.000 & 0.007 & 1.00 & 0.012 & 0.009 & 0.22 \\
\hline High CRP & -0.023 & 0.007 & 0.002 & -0.027 & 0.008 & $<0.001$ \\
\hline High fibrinogen & -0.008 & 0.007 & 0.26 & -0.005 & 0.008 & 0.56 \\
\hline$\sigma_{\text {int }}^{2}$ & 0.025 & 0.028 & $<0.001$ & -0.469 & 0.033 & $<0.001$ \\
\hline$\sigma_{\text {age }}^{2}$ & 0.000 & 0.000 & 1.00 & 0.000 & 0.000 & 1.00 \\
\hline$\sigma_{\text {int,age }}$ & 0.001 & 0.000 & $<0.001$ & 0.009 & 0.001 & $<0.001$ \\
\hline
\end{tabular}

Table 4. Age trajectories of gait speed among Britons aged 50 years and older. Source: ELSA $2004-2013$

inflammation and grip strength. However, this time the significant marker ${ }_{198}$ is fibrinogen. High levels of fibrinogen are associated with more than half a 199 kilogram reduction in grip strength (women: 545 gram, CI: $151-939 \quad 200$ gram; men: 710 gram, CI: $236-1,184$ gram).

Other findings can be briefly summarised. Socioeconomic positions 202 throughout the life course as indicated by wealth, occupation and 203 education showed largely significant associations with both measures of 204 physical function. Wealth (wealthiest and middle compared to the poorest 205 


\begin{tabular}{|c|c|c|c|c|c|c|}
\hline \multirow[t]{2}{*}{ Grip strength } & \multicolumn{3}{|c|}{ Women } & \multicolumn{3}{|c|}{ Men } \\
\hline & coef & s.e. & $\mathrm{p}$ & coef & s.e. & $\mathrm{p}$ \\
\hline Constant & 35.262 & 5.547 & $<0.001$ & 32.747 & 7.397 & $<0.001$ \\
\hline Age & -0.171 & 0.156 & 0.27 & 0.260 & 0.197 & 0.19 \\
\hline Age2 & -0.082 & 0.114 & 0.47 & -0.467 & 0.140 & $<0.001$ \\
\hline \multicolumn{7}{|c|}{ Cohort: Pre-Depression as reference } \\
\hline Depression era & 0.548 & 0.509 & 0.28 & 1.116 & 0.605 & 0.065 \\
\hline War & 0.173 & 0.675 & 0.80 & 2.481 & 0.840 & 0.003 \\
\hline Post-War & 0.194 & 0.857 & 0.82 & 3.153 & 1.110 & 0.005 \\
\hline Height & 0.011 & 0.004 & 0.002 & 0.020 & 0.004 & $<0.001$ \\
\hline \multicolumn{7}{|c|}{ Wealth: poorest third as ref. } \\
\hline Middle & 0.849 & 0.220 & $<0.001$ & 1.176 & 0.260 & $<0.001$ \\
\hline Wealthiest & 1.143 & 0.240 & $<0.001$ & 1.215 & 0.285 & $<0.001$ \\
\hline \multicolumn{7}{|c|}{ Education: primary school as ref. } \\
\hline High school & 0.680 & 0.240 & 0.005 & 0.561 & 0.323 & 0.082 \\
\hline College & 1.292 & 0.323 & $<0.001$ & 1.231 & 0.365 & $<0.001$ \\
\hline \multicolumn{7}{|c|}{ Occupation: routine manual as ref. } \\
\hline Managerial & -0.458 & 0.293 & 0.12 & 0.219 & 0.298 & 0.46 \\
\hline Intermed & -0.805 & 0.245 & 0.001 & -0.373 & 0.443 & 0.40 \\
\hline \multicolumn{7}{|c|}{ Marital status: separated/widowed as ref. } \\
\hline Single & -1.263 & 0.467 & 0.007 & -1.067 & 0.550 & 0.052 \\
\hline Married & -0.321 & 0.217 & 0.14 & 0.903 & 0.315 & 0.004 \\
\hline High CRP & -0.237 & 0.205 & 0.25 & -0.126 & 0.250 & 0.61 \\
\hline High fibrinogen & -0.545 & 0.201 & 0.007 & -0.710 & 0.242 & 0.003 \\
\hline$\sigma_{\text {int }}^{2}$ & 17.247 & 0.412 & $<0.001$ & 16.553 & 1.940 & $<0.001$ \\
\hline$\sigma_{\text {age }}^{2}$ & 0.025 & 0.004 & $<0.001$ & 0.064 & 0.005 & $<0.001$ \\
\hline$\sigma_{\text {int,age }}^{2}$ & -0.028 & 10.000 & 1.00 & -0.185 & 0.034 & $<0.001$ \\
\hline
\end{tabular}

Table 5. Age trajectories of grip strength among Britons aged 50 years and older. Source: ELSA 2004 - 2013

third), occupation (managerial and intermediate compared to routine 206 manual occupation), and education (college and high school compared to $\quad 207$ up to primary school leavers) have positive associations with both gait $\quad 208$ speed and grip strength, and are mostly statistically significant. A minor ${ }_{209}$ exception is noted where among women, intermediate occupation has a $\quad{ }_{210}$ significantly negative coefficient compared to routine manual occupation. $\quad{ }^{211}$ This may be due to more use of physical exertion in the routine manual ${ }_{212}$ occupation. 
Finally, to illustrate the contributions of all covariates to grip strength, ${ }^{214}$ we plot predicted values of grip strength in Figure 1. We refrained from ${ }_{215}$ presenting an analogous plot for gait speed since cohort indicators were not ${ }_{216}$ found significant; and from commenting on the shapes of the trajectories in ${ }_{217}$ Figure 1, relying on fit statistics in Table 3 to decide on the best model. In ${ }_{218}$ Figure 3, the four cohorts of men, marked with (M), are above the four $\quad{ }_{219}$ cohorts of women. Moreover, the War cohort (M) and the Post-War cohort ${ }_{220}$ (M) can be seen to be slightly above the older two cohorts (the Depression ${ }^{221}$ era cohort $(\mathrm{M})$ and the Pre-Depression era cohort $(\mathrm{M}))$. The statistical ${ }_{222}$ significance of the higher values should be gathered not from this figure $\quad{ }^{223}$ but from Table 5, which suggest that the two most recent cohorts of men ${ }^{224}$ attained significantly higher values. In contrast, in the women's sample ${ }_{225}$ there was no discernible difference in the four plots (clustered at the lower ${ }_{226}$ part), consistent with the lack of statistical significance shown in Table 5.227

\section{Discussion}

The trend of physical disability in older people, with its cost implications, ${ }^{229}$ has been uncertain given the countervailing drivers of extending life $\quad 230$ expectancy and reduction in disability at a given age [10,37. Our analysis ${ }^{231}$ uncovered a secular improvement in physical function that is most 232 pronounced among men born during and after the War. Unfortunately, no ${ }_{23}$ evidence of comparable gains accrued to women.

The data also revealed an intriguing pattern of improvement across ${ }^{235}$ physical function. The pattern is distinguished along normal capacity (gait ${ }^{236}$ speed at normal pace) versus maximum capacity (maximum grip strength). $\quad 237$ Among men, normal functional capacity did not show cross-cohort 
Figure 1. Predicted grip strength based on the best models. Source: ELSA $2004-2013$.
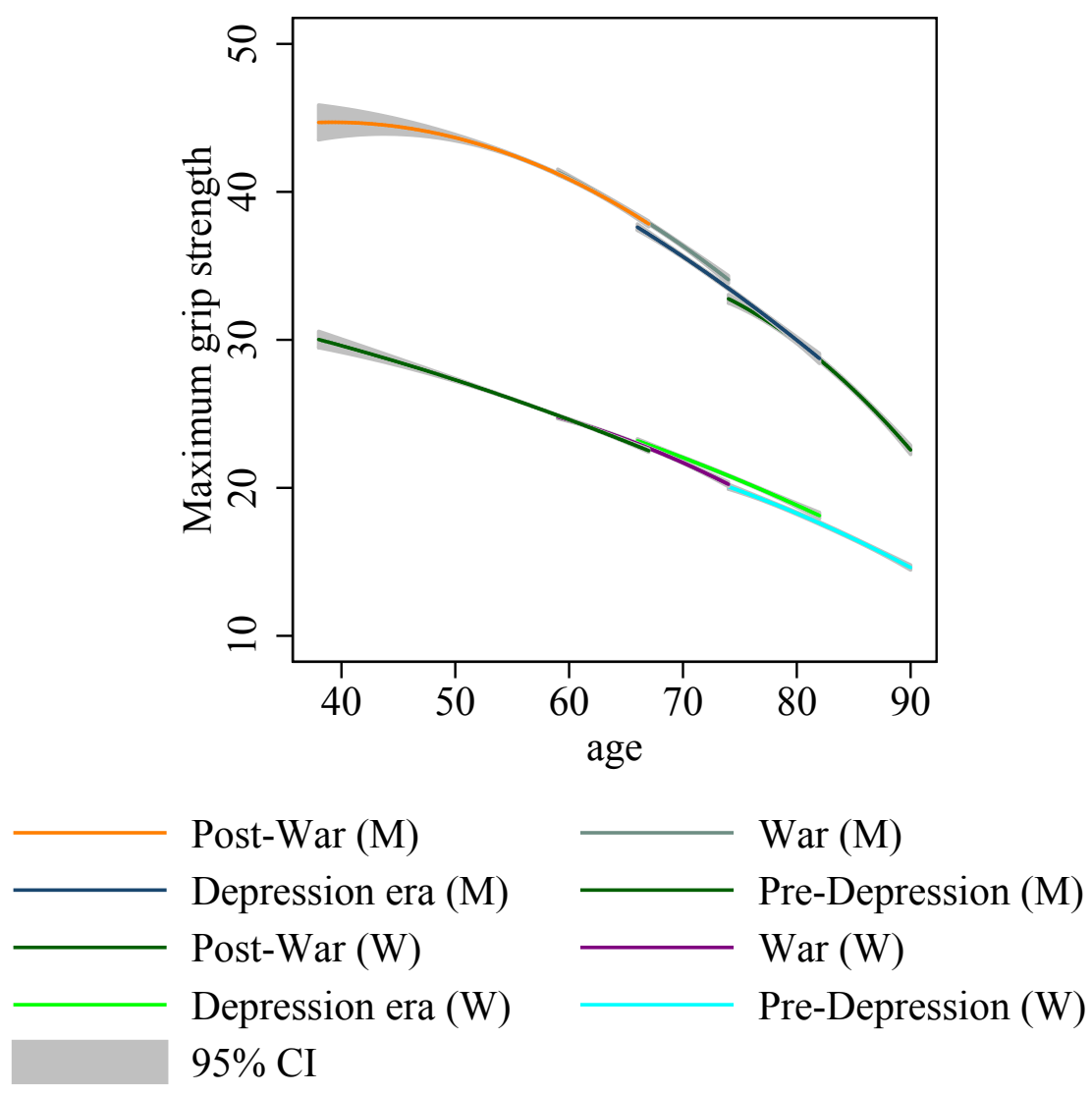

improvement at all but maximum capacity showed a secular improvement. 239 The maximum force that muscles can physically muster when called forth 240 has evidently increased across cohort considerably. This calls to mind that, ${ }^{241}$ in parallel, cognitive function in this sample has also been shown to 242 improve across cohort [1]. This is the first evidence of a complex pattern of ${ }_{243}$ improvement in trajectories of physical function across cohort and sex. $\quad 244$

The mechanism driving the cross-cohort improvement to health 245 functioning has generally been ascribed to general improvement in public ${ }_{246}$ health infrastructure and education [5, 38, 39]. Improvements in public $\quad 247$ 
health infrastructure from the early part of the last century meant that $\quad{ }_{248}$ children grew up with better conditions and reduced hazards and damage ${ }_{249}$ to health and child development. Improvements in education up to tertiary 250 levels meant that adults became better equipped to make use of the new ${ }_{251}$ information that was abundantly created and increasingly available $\quad 252$ through the parallel progress in science and medical technology. Although ${ }_{253}$ such developments have not resulted in uniform and secular improvement $\quad{ }^{254}$ in physical function, in maximum grip strength they have. Therein also ${ }_{255}$ lies a potential resolution to the uncertain trends in physical disability, i.e. ${ }^{256}$ different aspects of physical function give different pictures but maximum $\quad 257$ grip strength shows secular improvement.

A ground for optimism is thus available based on secular improvement $\quad{ }_{259}$ in maximum capacity among men. But as noted in the WHO World 260 Report on Ageing and Health [10] the daily functioning of an older person ${ }_{261}$ crucially depends on the surrounding health system environments and on ${ }_{262}$ access to such systems. Two older persons of the same cohort with 263 similarly low level of maximum capacity may fare and function differently ${ }_{264}$ depending on their access to assistive technology to compensate for the $\quad{ }^{265}$ perceived gap. Nevertheless, given the secular improvement in both 266 cognitive and physical functions among men, the more recent cohorts of $\quad 267$ the older population hold a double potential for continuing contribution $\quad{ }_{268}$ that may not have been fully appreciated.

Inflammation, on the other hand, is largely harmful across both measures of health function. Although different markers are found to be ${ }^{271}$ significant for different measures, inflammation is inversely related to $\quad 272$ maximum and normal functional capacity. Thus high fibrinogen associates 273 
with weaker grip while high CRP associates with slower gait. This gives ${ }^{274}$ some contrast to previous work on this sample. In a cross-section study of ${ }_{275}$ average grip strength, CRP has been found to be significant [40]. Our ${ }_{276}$ longitudinal study showed a similar sign but not significance. In 277 comparison with a cross-sectional observation, longitudinal observations $\quad{ }_{278}$ which were analysed with due control for attrition offer some advantage, $\quad 279$ particularly control for unobserved individual differences.

The inflammation effect echoes a finding based on this sample which $\quad{ }_{281}$ showed inflammation to be harmful to cognitive function [15]. Evidently, ${ }^{282}$ inflammation also goes with reduced physical function, supporting the idea 283 of inflammaging [41]. The mechanism for this revolves around the role of ${ }^{284}$ inflammatory cytokines in both muscle regeneration and muscle 285 functioning. In normal activities of daily living which involve muscle 286 exertion, some minute damage to muscle tissue may occur. In these $\quad 287$ circumstances, the pluripotent myosatellite cells respond by proliferating $\quad 288$ and differentiating to form muscle fibres and cover the damaged tissue. $\quad 289$ Circulating inflammatory cytokines such as tumour necrosis factor $\alpha \quad 290$ $(\mathrm{TNF} \alpha)$ have been shown to impair this process of regeneration in two $\quad{ }^{291}$ ways: apoptosis of myosatellite cells and inhibition of the differentiation $\quad{ }^{292}$ stage, leaving proliferated cells unable to differentiate and replace the $\quad 293$ damaged tissue. Beyond impairing the myogenesis process in common $\quad 294$ minute damage, inflammation also impairs functioning by reducing the $\quad 295$ power of the single permeable fibre. So in mice, TNF $\alpha$ rapidly reduces the ${ }^{296}$ force generating capacity or specific tension of muscle fibres independent of ${ }^{297}$ loss of muscle volume. In short, inflammation impairs muscle functioning ${ }^{298}$ in older people in at least three ways: it encourages myosatellite cell 
deaths, it interrupts the step of differentiation into myonuclei and muscle 300 fibres; lastly, even if muscle fibres have been successfully regenerated, 301 inflammation reduces the febrile tensile strength.

This study has a number of weaknesses. First, not all common measures 303 of inflammatory cytokines were collected, especially TNF $\alpha$. Addressing $\quad 304$ this should help in strengthening the mechanism by securing close comparison between population studies and in vitro studies. Since muscle 306 strength is determined to a large extent by muscle volume [42], a better ${ }_{307}$ measure of muscle volume using dual energy x-ray absorptiometry can $\quad 308$ additionally strengthen the basis for the mechanism underlying the 309 observed improvement. Lastly, the complex result on cohort improvement, 310 depending on aspects of physical function and sex, may be highly specific 311 to the British experience. A cross-country comparison is an obvious next 312 step. This study nonetheless has some strengths. First, the sample is 313 designed to represent the country and not only some clinical groups or $\quad 314$ regions, hence facilitating generalisation. Moreover, this is the first study, 315 based on repeated measures of both physical function and inflammation, to 316 draw trajectories of physical function and factors that shaped them as they 317 unfold with age. Finally, this study also derived the trajectories while 318 dealing with the attrition that is common but often ignored in longitudinal 319 ageing studies.

In conclusion, pronouncements about trends in healthy physical ageing 321 are marked with inconsistency 43 and some confusion [10]. Recent results 322 on cognitive ageing in Britain are reinforced with these newly uncovered $\quad 323$ results: among men both cognitive and physical functions are secularly $\quad 324$ improving. Future responses to the challenge of an ageing population [9] 325 
bioRxiv preprint doi: https://doi.org/10.1101/268334; this version posted February 21, 2018. The copyright holder for this preprint (which was not certified by peer review) is the author/funder, who has granted bioRxiv a license to display the preprint in perpetuity. It is made available under aCC-BY-NC-ND 4.0 International license.

by research and policy should carefully consider cohort composition to gain 326 useful insights and craft efficient policy. 


\section{Acknowledgments}

This work was supported by grants from the Medical Research Council and

Economic \& Social Research Council (No. G1001375/1), the National

Institute of Health Research (No. ES/L001772/1) and the European

Union's Horizon 2020 Research and Innovation Programme (No. 668648)

to Gindo Tampubolon. 


\section{References}

1. Tampubolon G. Cognitive ageing in Great Britain in the new century: Cohort differences in episodic memory. PLoS ONE. 2016 $12 ; 10(12): 1-17$.

2. Colcombe S, Kramer AF. Fitness effects on the cognitive function of older adults: A meta-analytic study. Psychological Science. $2003 ; 14(2): 125-130$.

3. Matsubayashi K, Okumiya K, Wada T, Osaki Y, Doi Y, Ozawa T. Secular improvement in self-care independence of old people living in community in Kahoku, Japan. The Lancet. 1996;347(8993):60.

4. Dodds RM, Syddall HE, Cooper R, Benzeval M, Deary IJ, Dennison EM, et al. Grip strength across the life course: Normative data from twelve British studies. PLoS ONE. 2014 12;9(12):1-15.

5. Tampubolon G. Growing up in poverty, growing old in infirmity: The long arm of childhood conditions in Great Britain. PLoS ONE. $201512 ; 10(12): 1-16$.

6. Zaninotto P, Sacker A, Head J. Relationship between wealth and age trajectories of walking speed among older adults: Evidence from the English Longitudinal Study of Ageing. The Journals of Gerontology Series A: Biological Sciences and Medical Sciences. 2013;68(12):1525-1531.

7. Sasaki H, Kasagi F, Yamada M, Fujita S. Grip strength predicts cause-specific mortality in middle-aged and elderly persons. The American Journal of Medicine. 2007;120(4):337 - 342 . 
8. Cooper R, Kuh D, Cooper C, Gale CR, Lawlor DA, Matthews F, et al. Objective measures of physical capability and subsequent health: a systematic review. Age and Ageing. 2011;40(1):14-23.

9. Christensen K, Doblhammer G, Rau R, Vaupel JW. Ageing populations: the challenges ahead. The Lancet.

2009;374(9696):1196-1208.

10. WHO. World Report on Ageing and Health. Geneve: WHO; 2015. Available from: WWW . who. int/ageing/publications/world-report-2015/.

11. Newman AB. An overview of the design, implementation, and analyses of longitudinal studies on aging. Journal of the American Geriatrics Society. 2010;58(S2):S287-S291.

12. Hardy SE, Allore H, Studenski SA. Missing data: A special challenge in aging research. Journal of the American Geriatrics Society. 2009;57(4):722-729.

13. Tampubolon G. Delineating the Third age: Joint models of older people's quality of life and attrition in Britain 2002-2010. Aging \& Mental Health. 2015;19:576-583. Available from: http://dx.doi.org/10.1080/13607863.2014.1003279.

14. Tampubolon G. Trajectories of the healthy ageing phenotype among middle-aged and older Britons, 2004-2013. Maturitas. 2016;88(7):9 15. 
15. Tampubolon G. Repeated systemic inflammation was associated with cognitive deficits in older Britons. Alzheimer's \& Dementia: Diagnosis, Assessment \& Disease Monitoring. 2016;3:1 - 6 .

16. Ferrucci L, Corsi A, Lauretani F, Bandinelli S, Bartali B, Taub DD, et al. The origins of age-related proinflammatory state. Blood. 2005;105(6):2294-2299.

17. Banks J, Breeze E, Lessof C, Nazroo J, editors. Retirement, health and relationships of the older population in England: The 2004 English Longitudinal Study of Ageing. London: The Institute for Fiscal Studies; 2006.

18. Banks J, Lessof C, Nazroo J, Rogers N, Stafford M, Steptoe A, editors. Financial circumstances, health and well-being of the older population in England: The 2008 English Longitudinal Study of Ageing. London: The Institute for Fiscal Studies; 2010.

19. Banks J, Nazroo J, Steptoe A, editors. The Dynamics of Ageing: Evidence from the English Longitudinal Study of Ageing 2002-2012 Wave 6. London: The Institute for Fiscal Studies; 2014.

20. Lima TAS, Adler AL, Minett T, Matthews FE, Brayne C, Marioni RE, et al. C-reactive protein, APOE genotype and longitudinal cognitive change in an older population. Age and Ageing. 2014;43(2):289-292.

21. Sujarwoto S, Tampubolon G. Inflammatory markers and physical performance in middle-aged and older people in Indonesia. Age and Ageing. 2015;44(4):610-615. 
22. Reiner AP, Aragaki AK, Gray SL, Wactawski-Wende J, Cauley JA, Cochrane BB, et al. Inflammation and thrombosis biomarkers and incident frailty in postmenopausal women. The American Journal of Medicine. 2009;122(10):947 - 954 .

23. Cohen HJ, Harris T, Pieper CF. Coagulation and activation of inflammatory pathways in the development of functional decline and mortality in the elderly. The American Journal of Medicine.

2003;114(3):180 - 187. Available from: http://www . sciencedirect.com/science/article/pii/S0002934302014845.

24. Schaap LA, Pluijm SMF, Deeg DJH, Visser M. Inflammatory markers and loss of muscle mass (sarcopenia) and strength. The American Journal of Medicine. 2006;119(6):526.e9 - 526.e17.

Available from: http://www.sciencedirect.com/science/ article/pii/S0002934305010545.

25. Marmot M, Banks J, Blundell R, Lessof C, Nazroo J, editors. Health, wealth and lifestyles of the older population in England: The 2002 English Longitudinal Study of Ageing. London: The Institute for Fiscal Studies; 2003.

26. Banks J, Breeze E, Lessof C, Nazroo J, editors. Living in the 21st century: older people in England: The 2006 English Longitudinal Study of Ageing. London: The Institute for Fiscal Studies; 2008.

27. Kröger H, Fritzell J, Hoffmann R. The association of levels of and decline in grip strength in old age with trajectories of life course occupational position. PLoS ONE. 2016;p. e0155954. 
28. Frederiksen H, Hjelmborg J, Mortensen J, McGue M, Vaupel JW, Christensen K. Age trajectories of grip strength: Cross-sectional and longitudinal data among 8,342 Danes aged 46 to 102. Annals of Epidemiology. 2006;16(7):554-562. Available from:

http://dx.doi.org/10.1016/j.annepidem.2005.10.006.

29. Andersen-Ranberg K, Petersen I, Frederiksen H, Mackenbach JP, Christensen K. Cross-national differences in grip strength among 50+ year-old Europeans: results from the SHARE study. European Journal of Ageing. 2009;6(3):227-236.

30. Spruit MA, Sillen MJH, Groenen MTJ, Wouters EFM, Franssen FME. New normative values for handgrip strength: Results from the UK Biobank. Journal of the American Medical Directors Association. 2013;14(10):775.e5 - 775.e11.

31. Kenny RA, Coen RF, Frewen J, Donoghue OA, Cronin H, Savva GM. Normative values of cognitive and physical function in older adults: Findings from The Irish Longitudinal Study on Ageing. Journal of the American Geriatrics Society. 2013;61:S279-S290.

32. Hernán MA, Brumback B, Robins JM. Marginal structural models to estimate the causal effect of zidovudine on the survival of HIV-positive men. Epidemiology. 2000;11(5):561-570.

33. Cole SR, Hernán MA, Margolick JB, Cohen MH, Robins JM. Marginal structural models for estimating the effect of highly active antiretroviral therapy initiation on CD4 cell count. American Journal of Epidemiology. 2005;162(5):471-478. 
34. Cole SR, Hernán MA. Constructing inverse probability weights for marginal structural models. American Journal of Epidemiology. $2008 ; 168(6): 656-664$.

35. Gottesman RF, Rawlings AM, Sharrett AR, Albert M, Alonso A, Bandeen-Roche K, et al. Impact of differential attrition on the association of education with cognitive change over 20 years of follow-up: The ARIC Neurocognitive Study. American Journal of Epidemiology. 2014;179(8):956-966.

36. Vermunt JK, Magidson J. Upgrade Manual for Latent GOLD 5.1. Belmont, MA: Statistical Innovations; 2016.

37. Cutler DM. Declining disability among the elderly. Health Affairs. $2001 ; 20(6): 11-27$.

38. Deaton A. The Great Escape: health, wealth, and the origins of inequality. Princeton, NJ: Princeton University Press; 2013.

39. Marmot M. The Health Gap: The Challenge of an Unequal World. London: Bloomsbury; 2015.

40. Hamer M, Molloy GJ. Association of C-reactive protein and muscle strength in the English Longitudinal Study of Ageing. AGE. 2009;31(3):171-177. Available from: http://dx.doi.org/10.1007/s11357-009-9097-0.

41. Franceschi C, Campisi J. Chronic inflammation (Inflammaging) and its potential contribution to age-associated diseases. The Journals of Gerontology Series A: Biological Sciences and Medical Sciences. 2014;69(Suppl 1):S4-S9. 
42. Degens H. The role of systemic inflammation in age-related muscle weakness and wasting. Scandinavian Journal of Medicine \& Science in Sports. 2010;20(1):28-38.

43. Beard JR, Officer A, de Carvalho IA, Sadana R, Pot AM, Michel JP, et al. The World report on ageing and health: a policy framework for healthy ageing. The Lancet. 2015;387(10033):2145-2154. 